\title{
Presentación del Atlas de Monterrey, coordinado por Gustavo Garza Villarreal
}

\section{Comentarios de Víctor L. Urquidi *}

El Atlas de Monterrey, a cargo del doctor Gustavo Garza Villarreal y un grupo importante de colaboradores, publicado recientemente por el Instituto de Estudios Urbanos de Nuevo León, con la colaboración del Gobierno del Estado de Nuevo León, la Universidad Autónoma de Nuevo León y El Colegio de México, constituye un documento de gran valor para la planeación urbana de esa gran ciudad mexicana y como ejemplo del tipo de estudios que sería necesario para tal fin en cualquier centro urbano importante del país que piense en su futuro. Los auspiciadores y los autores merecen, en consecuencia, una calurosa felicitación por la realización de este trabajo y por ponerlo a la disposición del público en tan corto tiempo.

Desde el punto de vista profesional, la obra responde ampliamente a la pregunta de cuál lıa sido la función de este magno centro industrial, Monterrey -con el que se han trazado paralelos en América Latina con Medellín, Colombia, Córdoba, Argentina o Belo Horizonte, Brasil-, y cuál sería su proyección o devenir en el conjunto nacional. La historia de Monterrey, en México, es singular, ya que se adentró muy temprano en el cauce de la industrialización sin pasar por todas las etapas de otras grandes ciudades del mundo situadas en poderosas áreas agropecuarias, o en puertos y ríos navegables, o en medio de comunicaciones transcontinentales como centros comerciales. Estoy consciente de que, según el Atlas, Monterrey fue en su primera historia un centro comercial y tuvo un "comercio significativo" a mediados del siglo xix. Pero hay que guardar las proporciones: en 1900 la población no rebasaba los 70000 habitantes, y aun en 1940 se cifraba en 200000 . El Monterrey de hoy, el Área Metropolitana (AMM) de 2.5 millones -comparable en número a Atlanta o a Seattle-Tacoma- es ante todo un centro industrial y de servicios productivos.

De cualquier manera, la parte histórica es merecedora de la mayor atención, ya que es el antecedente de muchos elementos del Monterrey de hoy. Pero asimismo cabe centrar la atención en la influencia del desarrollo económico general de México en este Monterrey actual, así como a su vez en la pujanza y características de Monterrey en el crecimiento industrial de México en su conjunto.

\footnotetext{
* Profesor emérito de El Colegio de México.
} 
El Atlas amplía, enriquece y encuadra una serie de trabajos que a lo largo de los años han venido haciendo planificadores urbanos, economistas, demógrafos y otros especialistas -tarea en la que sin duda han participado también otros actores del cambio, entre ellos el sector público, el sector privado y la sociedad civil. Es evidente que la expansión del Área Metropolitana, tan sólo desde los años treinta, ha sido explosiva, a través de un proceso acumulativo de industrialización -desde algunas bases creadas ya en el siglo xIx, con incorporación sucesiva de nuevos horizontes industriales y tecnológicos.

El capítulo 3, en particular, analiza esta rápida evolución y los cambios en la estructura económica del AMM. Para 1960, el producto manufacturero en el nivel nacional representaba $18.7 \%$ del PIв de México, mientras que el de Monterrey era ya 37\% del PIB de esa ciudad (también, por cierto, el comercio significaba en el PIв de Monterrey más que en escala nacional). El periodo 19601970 fue de enorme crecimiento industrial en Monterrey, de casi $10 \%$ anual, y todavía en el decenio 1970-1980 fue de $6.3 \%$ anual. En 1980, la producción manufacturera en Monterrey representó $39 \%$ del PIB local, mientras que en el nivel nacional la cifra comparable fue de $23 \%$. Junto con la expansión industrial, el AMM experimentó crecimientos a una tasa aún más elevada de su PIB en el sector transporte, el de construcción y el de servicios. El doctor Gustavo Garza en el capítulo 3.2, reafirma, con razón, que entre 1960 y 1988, "la industria es el símbolo de Monterrey", y recalca además el incremento de los servicios al productor y de las actividades terciarias en general -que son objeto de otro capítulo de gran interés escrito por Fernando Pozos Ponce en que se destaca el incremento del empleo en estas ramas.

Al mismo tiempo, los análisis del capítulo 3.6 muestran la especialización industrial del AMM entre 1960 y 1980, con creciente concentración del PIB manufacturero en las ramas de productos alimenticios, productos metálicos básicos, minerales no metálicos, química, automotriz, de maquinaria, artículos eléctricos, papel y cartón, y por supuesto una larga lista - evidencia de la cada vez mayor diversificación y articulación- de otras ramas, algunas tradicionales y otras nuevas.

En cambio, la crisis nacional de los años ochenta encontró a Monterrey bastante vulnerable; se registró un descenso de su PIB manufacturero, con menor participación en el PIB industrial de México para 1988. Se ha evidenciado, por otro lado, alguna recuperación entre 1989 y 1991, pero de nuevo se registró un descenso en 1992. Según los autores del Atlas, la industria regiomontana no ha salido aún de la crisis de los años ochenta, que se relaciona con el 
"agotamiento de un ciclo tecnológico de largo plazo" en las ramas tradicionales, entre ellas la metal-mecánica y la metálica básica (p. 13), no obstante que al mismo tiempo muchas industrias se han acercado a los paradigmas tecnológicos de avanzada, necesacios para la competitividad en el nuevo ambiente de apertura y slobalización de mercados.

La urbanización de Monterrey y la constante ampliación del \MM son objeto de análisis igualmente acuciosos en la obra conentada. La industrialización rápida atrajo fuerza de trabajo y tgigantó la ciudad, que pronto rebasó los límites municipales inisiales. La industria, a su vez, se extendió a municipios aledaños, mnque en el Pाв industrial siguen predominando el municipio de Monterrey y el de San Nicolás. Como en el caso histórico de mushas otras ciudades, la actividad económico-industrial y comersial iba muy adelante de los avances urbanísticos. En el camino se medaron muchos aspectos urbanos sin resolver, y el torbellino de os últimos 40 años ha hecho bastante más compleja y costosa la solución de cualquier aspecto urbano aislado.

Teniendo en cuenta lo anterior, es de mayor importancia aún mtrar en las consideraciones sobre los escenarios futuros y las sroyecciones que se presentan en los capítulos 8 y 9 . En cuanto a a población futura, parece haber acuerdo en que para el año 2000 lifícilmente se rebasará la cifra de 3.25 a 3.5 millones de habitanes, en contraste con los 5 millones que se suponían hace unos 25 iños. Aparte de problemas derivados del Censo General de Pobla:ión de 1990, que según connotados demógrafos parece padecer le subenumeraciones en muchas partes del país, es evidente que a tasa global de fecundidad en el AMM se ha reducido en propor:ión no previsible en decenios anteriores; por otro lado, la espeanza media de vida es la más elevada de México. Monterrey está ra en la etapa de la transición demográfica. Además el fortísimo :omponente de la migración hacia Monterrey y Nuevo León en 'eneral se ha atenuado en medida considerable y, según las prorecciones, por causas diversas, la inmigración neta no desempeiará en el futuro un papel significativo -pudiera haber inclusive mmigración neta.

Como en México en su conjunto la tasa global de fecundidad e ha reducido en los últimos quince años, es de suponer que Monterrey, que ha llevado la delantera en este descenso, adquiriá, sobre todo después del año 2000 , las características de una urıe más asentada, lo que ofrecerá mejor oportunidad para hacer rente a carencias educativas, de salud, de vivienda, de servicios urbanos y otros, siempre que las condiciones económicas y fiscaes lo permitan. Llegar a 5 millones de habitantes, en la gran área 
urbana para el año 2020, no será tan inmanejable como se desprendía de las condiciones demográficas y otras de hace dos o tres decenios. Y si otras áreas del norte, en especial las de Coahuila y Tamaulipas, llegan a experimentar desarrollo económico adecuado, la menor atracción migratoria hacia Monterrey dejará un fuerte respiro -razón por la que deberá estudiarse con gran atención la relación entre el desarrollo de Monterrey y de Nuevo León con el de esos dos estados y, además, con la zona fronteriza en general.

En la proyección económica, sintetizada en un índice todavía demasiado simplificado -el del crecimiento medio del PIB-, cabría a mi juicio explorar mayor número de alternativas, puesto que las instancias de incertidumbre son mucho mayores. De entrada, yo no confiaría mucho en que el piB nacional pudiera crecer a una tasa media anual de $6 \%$ de aquí al año 2010 , tanto por restricciones externas como internas. La mínima o moderada de $3.5 \%$ que supone el estudio se acercaría más a una posible realidad viable (si pudiera llegar a $4.5 \%$, tanto mejor). Lo más probable es que el crecimiento previsible de la economía mexicana en su conjunto no se reflejaría en una expansión suficiente de los volúmenes de empleo formal, lo cual plantea problemas no sólo para Monterrey sino para otras regiones cercanas.

Desde luego que una cosa es lo que pase a nivel nacional y otra lo que suceda en el área económico-industrial y de servicios de Monterrey y sus alrededores. El estudio supone que el PIB del AMM pueda crecer a $6 \%$ anual entre los años 2000 y 2010 , es decir, en realidad a mayor velocidad que la economía nacional en su conjunto en una proyección prudente de ésta. Si se cumple esta proyección, también se facilitará la solución de los problemas urbanos de toda índole y se marchará hacia la "megalopolización" con Saltillo. Son estos temas obligados de investigación y de proyecciones alternativas para Monterrey que espero se lleven a cabo. Se menciona que la consolidación del TLCAN podría ayudar a llevar a Monterrey a las grandes alturas, y supongo que tendrá bastante que ver con las integraciones específicas, vía exportación, con los mercados de Estados Unidos y la creación de bases generales de exportación a otras áreas del mundo. Son muchos los factores por considerar y sería todavía prematuro, sobre todo en las condiciones actuales de incertidumbre, colocarse en la vía del optimismo sin cortapisas. Monterrey está también vinculado a gran parte del resto de la economía mexicana, y no puede aislarse de tendencias internas que pudieran ser menos favorables.

Ahora bien, la planificación urbana requiere hacerse para las buenas y para las malas, de manera que las ideas generales no deberán depender de tal o cual diferencia en la tasa de incremento 
del PIB prevista, sobre todo considerando una sola dimensión agregada como ésta. Por lo menos, habría que entrar en cambios previsibles de la estructura económica, y en los que de manera más concreta deriven de las innovaciones tecnológicas en la industria y los servicios y de la capacidad de gestión empresarial frente a la competencia internacional. Ello no quiere decir que se pueda hacer planificación urbana en abstracto, ya que tiene un componente de costo y beneficio y de aspectos prácticos de financiamiento e inversión, que determinarían distintas soluciones estructurales y a través de los tiempos. Deberá verse como un sistema en que los factores económicos y los sociales interactúen con los propiamente urbanos o urbanísticos, con retroalimentaciones tanto positivas como negativas, en un mundo de creciente complejidad y diversidad.

Resulta muy valiosa la serie de antecedentes que el capítulo 8 del Atlas presenta sobre los planes reguladores y directores de Monterrey y acerca del primer Plan Director de Monterrey, formulado hacia 1966 -que, según leo, ha tenido aplicaciones parciales- y que iba mucho más allá de los llamados planos reguladores. Dicho Plan Director tenía en cuenta precisamente el resto de los elementos que, sujetos a factores económicos y sociales, entrarían en la determinación de la conformación futura de una ciudad. Se han mantenido y ampliado las consideraciones básicas en los planes de desarrollo urbano recientes y en la previsión para el periodo que corre hasta el año 2010 en relación con el AMm y el contexto de la programación urbana nacional.

Las condiciones de hoy son, por supuesto, distintas a las de fines de los años sesenta. Monterrey y sus municipios, el AMM, ya creció, con todas las características, buenas o malas, que se han anotado y analizado, sin atenerse a un plan director. Los problemas de base, muchos de ellos previsibles y no atendidos, ahí están, y la estructura de ingresos de la población quizá no dé para más, como asimismo las posibilidades financieras del sector público han padecido severas limitaciones. Lo importante, no obstante, es establecer metas y a la vez profundizar en los cambios de las condiciones básicas que se requieren para hacer viable alcanzar esas metas. Es obvio que a las tradicionales condiciones de vivienda, agua y drenaje, transporte y vialidad, habría que añadir las ambientales (que el capítulo 5 detalla alarmantemente) y las de calidad de vida en general.

Al final del capítulo 8 se plantea una gran disyuntiva: la de consolidar la metropolización de Monterrey o lograr una descentralización urbana intraestatal. Y al final del capítulo 9 se plantea otra: la de la consolidación metropolitana o la "megalopolización" de Monterrey hacia el año 2020, es decir, la extensión del área 
metropolitana a la vecina zona de Saltillo y sus alrededores en Coahuila.

Tengo la impresión de que no son verdaderas disyuntivas, sino partes de una conformación urbana futura que todavía no se alcanza a vislumbrar bien. La descentralización intraestatal no tiene por qué verse como alternativa a la consolidación de la metropolización, sino como un aspecto complementario. La metropolización va a ocurrir de cualquier manera, aunque no debiera seguir las tendencias medio caóticas actuales sino integrar determinadas áreas de trabajo con áreas de vivienda a base no de pequeñas unidades individuales sino de complejos habitacionales, recreativos, administrativos, educativos y comerciales, de salud, etc., donde predominen edificios de varios pisos, con economía en el uso del suelo y en la infraestructura. Ello reduciría las necesidades de transportación de unos extremos a otros, y las "idas al centro" que tanto caracterizan a las ciudades mexicanas.

A este proceso, en bien del mejoramiento ambiental y de la eficiencia urbana, debieran acompañarlo, como en todas las grandes ciudades del mundo, modernos sistemas de transporte colectivo subterráneo o de superficie, de gran capacidad, así como sistemas de comunicación electrónica eficaces. La mayor parte del movimiento cotidiano al trabajo, al comercio, a los servicios generales, se haría dentro de los complejos citados. Las comunicaciones modernas y la telemática se encargarían de comunicar unos complejos con otros. Las ciudades "satélite" puramente habitacionales no resuelven el problema, como ya se ha visto en muchas partes del mundo; hay, por otra parte, ejemplos buenos de ciudades periféricas integradas internamente en todos sus aspectos, como varias que circundan a París.

Y en cuanto a la gran área megalopolitana que se extendería a Saltillo, tampoco veo que esta idea se contraponga con la metropolización de Monterrey en sí o de Saltillo en sí. Ambas metrópolis pueden buscar su propia optimización como tales y, en su momento, enlazarse de manera conveniente. Entre otras cosas, ello dependerá de las relaciones inter-industriales de las dos metrópolis, a medida que avancen sus conformaciones de manufacturas y de servicios. La descentralización industrial en ambos estados podría coordinarse en función de la probable meta de la metropolización respectiva y la futura creación del área "megalopolitana".

Con lo anterior quiero decir, simplemente, que a las ciudades no se les puede considerar como islas u oasis -o como basureros industriales- sino como manifestaciones de un conjunto o de varios conjuntos en los que interactúen los factores económicos, sociales, políticos y culturales, y que en determinados periodos his- 
tóricos se puedan definir en materia de metas y de resultados esperados para mejorar la calidad de vida de las poblaciones.

Mi recorrido por este novedoso Atlas de Monterrey - una especie de marcha hacia la macrociudad-me ha sido muy provechoso, y nie ha suscitado constantemente preguntas sobre la relación de Monterrey con el resto de la economía nacional y con otras partes del mundo. No es el caso ahora de abrir otra gran área de disquisiciones, más allá del propósito de la obra. Por ello, para terminar, me limito a reiterar a los autores del Atlas mi felicitación por un trabajo muy bien logrado, haciendo votos por que de él deriven muchas otras investigaciones en el terreno del desarrollo urbano, de utilidad tanto para el estado de Nuevo León como para las grandes y medianas ciudades del resto de la República, teniendo siempre en cuenta las tendencias de las políticas y las variables generales del desarrollo económico y social. 
